\section{ИСПОАЬЗОВАНИЕ 4\%}

\section{АРТИКАИНА В СОЧЕТАНИИ С ЭПИНЕФРИНОМ}

\section{(1: 100000 И 1: 200 000) В ПРАКТИКЕ АЕТСКОГО CTOMATONOГA}

\author{
ОПИСАНИЕ КАИНИЧЕСКИХ САУЧАЕВ
}

Одним из самых важных и революционных достижений медицины XIX века стало открытие общего обезболивания и начало «эры анестезии». Отцами-основателями наркоза являются такие исследователи, как дантист Уильям Мортон, врач и химик Чарльз Джексон, дантист Гораций Веллс и доктор Кроуфорд Лонг, чьи приоритеты открытия дискутируются и в наше время, а развитие местной анестезии связывают с такими именами, как Василий Анреп и Карл Коллер [1].

Целью медицинской науки 20-21 веков стала разработка и экспериментальное обоснование методов местной анестезии и поиска/синтеза современных высокоэффективных анестетиков, а также внедрения их в медицинскую практику. Безусловно, внедрение высокоэффективных местных анестетиков в медицину, и в том числе в стоматологию, имеет огромное социальное значение.

К сожалению, распространенность основных стоматологических заболеваний населения в РФ в целом остается на высоком уровне во всех возрастных группах. Особую тревогу представляет высокий уровень множественного кариеса у детей. По современным данным ряда авторов, распространенность кариеса временных зубов в России в 3-летнем возрасте составляет $57,7 \%$, в 6-летнем возрасте колеблется от 77,6 до $86,1 \%$ при интенсивности от 2,54 до 4,37, а в 8 лет возрастает до 82,4-93,4\% при индексе интенсивности от 3,7 до 8,25 . Распространенность кариеса постоянных зубов у детей в 6 лет составляет 33,2-44,5\%, в 12 лет - 55,6$72,3 \%$, достигая к 15 годам 70,2-94,3\% [3, 4]. Поэтому оказание стоматологической помощи детям является важной задачей, а качественная стоматологическая помощь невозможна без применения эффективной и безопасной анестезии.

Основными требованиями к местной анестезии в детской стоматологии, с учетом особенностей физиологии и психоэмоционального статуса, являются безопасность и эффективность препаратов при минимальных терапевтических дозах. Одним из основных местных высокоэффективных анестетиков на рынке стоматологических услуг в настоящее время является артикаин из группы амидов. Особенностями артикаина являются: высокая скорость всасывания препарата, хорошая диффузионная способность, низкая токсичность, высокая активность, большая скорость элими-

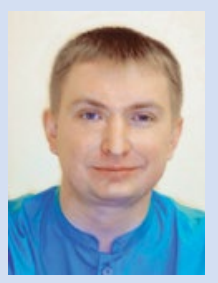

Иощенко Е.С. к.м.н., доцент кафедры стоматологии детского возраста и ортодонтии ГБОУ ВПО УГМУ, г. Екатеринбург

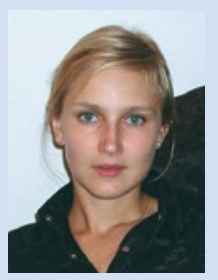

Брусницына E.B. к.м.н., ассистент кафедры стоматологии детского возраста ГБОУ ВПО УГМУ, г. Екатеринбург

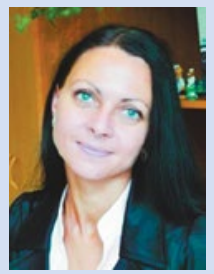

Ожгихина Н.В. к.м.н., доцент кафедры стоматологии детского возраста и ортодонтии ГБОУ ВПО УГМУ, г. Екатеринбург, kdvo@inbox.ru

\section{Резюме}

Оказание стоматологической помощи детям в настоящее время является важной задачей, а качественная стоматологическая помощь невозможна без применения эффективной и безопасной анестезии. Одним из основных местных высокоэффективных анестетиков является артикаин из группы амидов. В статье рассматриваются два клинических случая с использованием в клинической практике детской стоматологии артикаинсодержащего препарата Ультракаин ${ }^{\circledR}$.

Ключевые слова: местная анестезия, детская стоматология, артикаин.

USING 4\% ARTICAINE COMBINED WITH EPINEPHRINE (1: 100,000 AND 1: 200,000) IN THE PRACTICE OF PEDIATRIC DENTISTRY: CLINICAL CASES DESCRIPTION

loschenko E.S., Brusnitsyna E.V., Nersessian P.M., Zakirov T.V., Ozhgihina N.V.

\section{The summary}

Dental care for children at the moment is an important task. A high-quality dental care is impossible without the use of safe and effective anesthesia. One of the main local anesthetics of high-performance dental services is the amide anesthetic articaine. This article discusses two clinical cases using in clinical practice of pediatric dentistry of articaine-containing drug Ultracaine ${ }^{\circledR}$.

Keywords: anesthesia, Dentistry of childhood, articaine. 


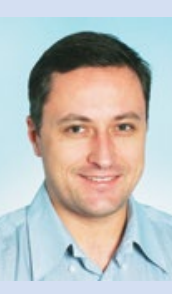

Закиров Т.В.

к.м.н., доцент кафедры стоматологии детского возраста и ортодонтии ГБОУ ВПО УГМУ, г. Екатеринбург

Нерсесян П.М. ассистент кафедры хирургической стоматологии и челюстно-лицевой хирургии ГБОУ ВПО УГМУ

нации $[2,5]$. Преимуществом использования артикаина является образование нетоксичной артикаиновой кислоты благодаря механизмам биотрансформации ферментными системами печени и эстеразами тканей и крови. Элиминация артикаина происходит быстрее других амидных анестетиков. Высокая степень диффузии артикаина способствует расширению показаний к инфильтрационной анестезии, уменьшая тем самым необходимость в проведении болезненной проводниковой мандибулярной анестезии у детей $[2,5]$.

Важно уметь рассчитывать максимальную дозу местного анестетика. Для артикаина максимальная доза для детей составляет 5 мг/кг (например, в одной карпуле 1,7 мл содержится 68 мг артикаина). Европейская Ассоциация по обезболиванию в стоматологии (EFAAD) не рекомендует использовать однократно более 50\% максимальной дозы анестетика [2].

На современном фармацевтическом рынке присутствует большое количество анестетиков, содержащих артикаин. Разберем несколько клинических случаев с использованием в клинической практике детской стоматологии артикаинсодержащего препарата Ультракаин®, который демонстрирует высокую эффективность и безопасность на протяжении многих лет [6].

\section{Клинический случай 1.}

В стоматологическую клинику обратились родители 7-летней девочки с жалобами на кариозные полости у ребенка.

При объективном осмотре на контактных поверхностях зубов 6.4, 6.5 определяются_кариозные полости, в пределах околопульпарного дентина сообщающиеся с полостями зубов. Сообщения с полостями зубов болезненны при зондировании, пульпа кровоточит. Патологических изменений в периапикальных тканях зубов 6.4, 6.5 рентгенологически не выявлено.

Был диагностирован хронический фиброзный пульпит 6.4, 6.5 (МКБ К04.0 - пульпит).

В соответствии с возрастом ребенка была выбрана методика инфильтрационной анестезии с использованием препарата 4\% артикаина, содержащего вазоконстриктор эпинефрин 1:200 000 (Ультракаин ${ }^{\circledR}$ Д-С,
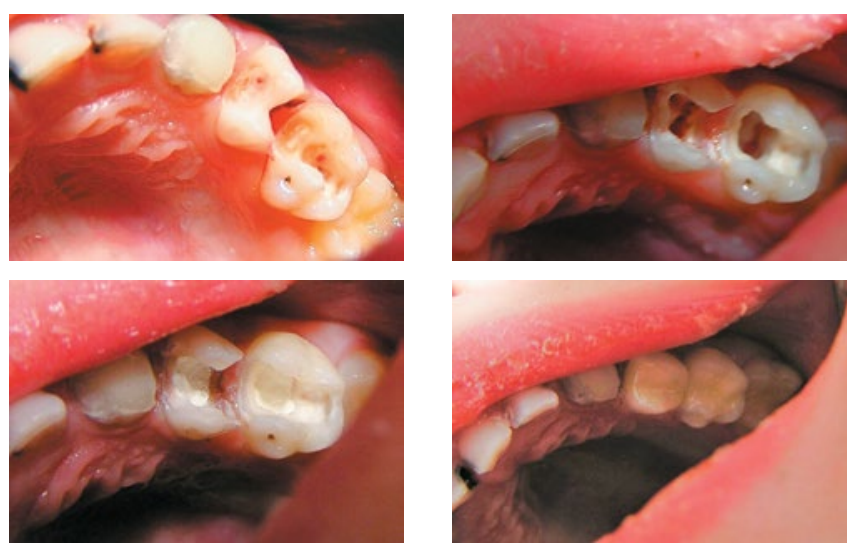

Рис. 1

Германия). Основанием для расчета дозы анестетика являлась масса тела нашего пациента. При весе ребенка 25 кг максимальная терапевтическая доза используемого препарата, согласно инструкции, составляет 125 мг артикаина или 3,1 мл раствора (или 1,8 карпулы). В соответствии с рекомендованным однократным введением анестетика детям в дозе $1 / 2$ от максимальной $[2,3]$ было введено 1,55 мл артикаина или примерно 9/10 карпулы Ультракаин® Д-С. Выбор концентрации вазоконстриктора был обоснован возрастом ребенка и объемом медицинского вмешательства. Выбор анестетика с более высокой концентрацией вазоконстриктора в данном клиническом случае (например, Ультракаин ${ }^{\circledR}$ Д-С форте 1:100 000) нецелесообразен, так как его высокая концентрация влияет в основном лишь на длительность анестезии [2, 5], а в детском возрасте это может привести к рискам таких осложнений, как прикусывание губ, щек и т.д., а также некрозу мягких тканей в связи с длительной ишемией, обусловленной физиологическими особенностями детского организма в этом возрасте - высоким тонусом симпатической нервной системы [2]. Использование препарата Ультракаин® Д без вазоконстриктора не окажет должного анестезирующего эффекта по глубине и продолжительности действия при выбранном методе лечения.

Под инфильтрационной анестезией с использованием Ультракаин ${ }^{\circledR}$ Д-С проведено лечение зубов $6.4,6.5$ в полном объеме методом витальной ампутации: препарирование кариозной полости, ампутация, механическая и медикаментозная обработка, пломбирование устьев корневых каналов цинк-оксид-эвгеноловой пастой, постановка пломбы (рис. 1). Проведение всех манипуляций было безболезненным, комфортным, показало высокую клиническую эффективность выбранного нами местного анестетика. Побочных реакций при проведении анестезии не было.

\section{Клинический случай 2.}

В стоматологическую клинику обратились родители 13-летнего ребенка с жалобами на выбитый в результате спортивной травмы зуб. Зуб принесли в емкости с молоком. Травма была 2 часа назад.

При объективном осмотре: зуб 2.1 отсутствует, лунка выбитого зуба заполнена свертком крови, 

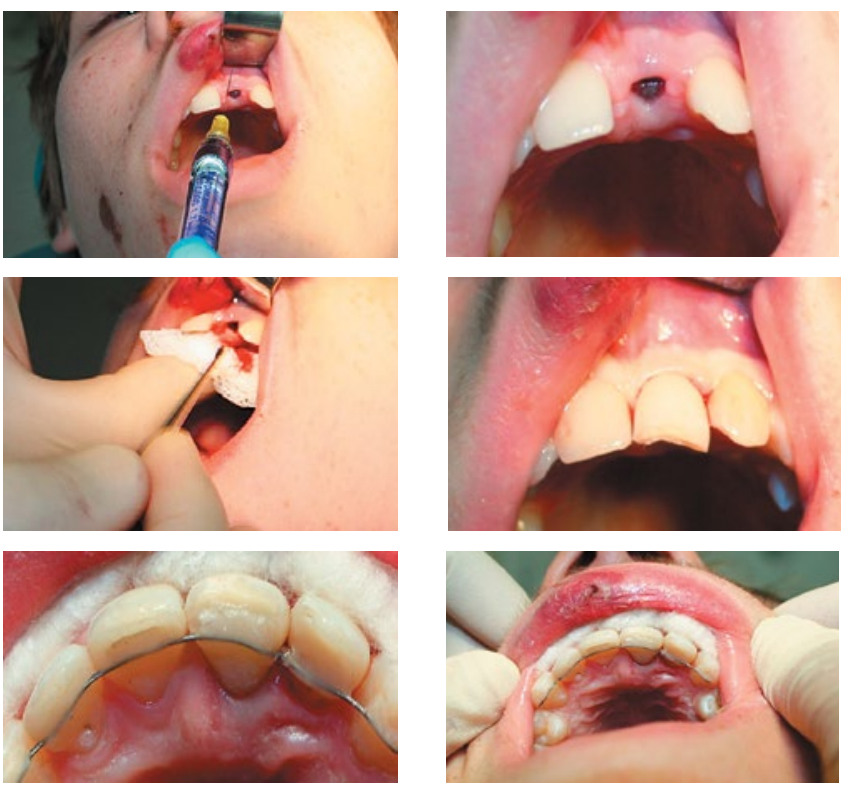

Pис. 2

кортикальная пластинка альвеолярного отростка в области выбитого зуба сохранена.

Диагностирован полный вывих зуба 2.1 (МКБ S03.2 - вывих зуба).

Для эффективного и пролонгированного местного обезболивания, с учетом тяжести травмы, объема лечебных манипуляций и возраста, была проведена инфильтрационная и проводниковая анестезия у резцового отверстия, с использованием Ультракаин® Д-С форте с содержанием вазоконстриктора 1:100 000. Использование артикаинсодержащего препарата c меньшей концентрацией в данном клиническом случае не оказало бы должного обезболивающего эффекта. При весе ребенка 45 кг максимальная терапевтическая доза артикаина, согласно инструкции, составила 225 мг или 5,6 мл (3,3 карпулы). В соответствии с рекомендованным однократным введением анестетика детям в дозе $1 / 2$ от максимальной [2] была рассчитана доза введения артикаина 2,8 мл или примерно 1,5 (полторы) карпулы Ультракаин® Д-С форте, каждая из которых содержит 1,7 мл раствора.

Проведена репозиция зуба 2.1 и шинирование сроком на 4 недели. Спустя 2 недели после репозиции и шинирования зуба 2.1 была проведена экстирпация с пломбированием корневого канала (рис. 2). Пациент взят на диспансерное наблюдение. Методика лечения при данной клинической ситуации показала высокую эффективность анестетика: полную безболезненность манипуляций и хорошую переносимость. Побочных реакций при проведении анестезии не было.

Использование любых препаратов для местной анестезии должно соответствовать принципам расчета максимально допустимых и однократных доз для артикаина. Так, согласно инструкциям для применения, для пациентов детского возраста (старше 4 лет) доза препарата Ультракаин® Д-С и Ультра- каин ${ }^{\circledR}$ Д-С форте подбирается в зависимости от возраста и массы тела ребенка, но она не должна превышать 5 мг артикаина на 1 кг массы тела.

Выбор концентрации вазоконстриктора основывается на анатомических, физиологических, поведенческих особенностях детского организма и состояния здоровья. Использование артикаина для местной анестезии в практике детской стоматологии возможно с четырех лет [7, 8]. При проведении малоинвазивных, недлительных лечебных манипуляций, а также у детей младше 5 лет использование вазоконстриктора в составе местного анестетика не рекомендуется из-за риска осложнений. В данном случае может быть рекомендован Ультракаин® Д (без содержания эпинефрина), продолжительность анестезии составляет примерно 20 минут. В то же время стоит с осторожностью применять анестетики без вазоконстриктора, так как их быстрая системная абсорбция может способствовать передозировке [9]. Для проведения большинства манипуляций стоматологического лечения без необходимости длительного пролонгированного эффекта местного обезболивания для детей старше 5 лет оптимальным является Ультракаин ${ }^{\circledR}$ Д-С с содержанием эпинефрина 1:200 000. Использование Ультракаин ${ }^{\circledR}$ Д-С форте, с содержанием эпинефрина 1:100 000, рационально при травматичном и длительном вмешательстве.

Таким образом, клиническое применение препаратов Ультракаин® показывает его высокую эффективность в детской стоматологии: дает возможность качественной, безболезненной и безопасной санации стоматологических заболеваний у детей.

\section{ЛИТЕРАТУРА}

1. Грицук С.Ф. Анестезия в стоматологии. - М.:«Медицинское информационное агенство», 1998. - 304 с.

2. Особенности обезболивания при лечении стоматологических заболеваний у детей / Под ред. проф. С.А.Рабиновича. - М.: МЕДпресс-информ, 2005. - 120 с.

3. Русакова И.В. Оценка состояния стоматологического здоровья населения Свердловской области и факторов, влияющих на развитие основных стоматологических заболеваний: автореф. дис. ...канд. мед. наук: 14.00.21 / Русакова Ирина Владимировна; Уральская гос. мед. акад. - Екатеринбург, 2008. - 21 с.

4. Стоматологическая заболеваемость населения России / Под ред. Э.М.Кузьминой. - М., 2009.

5. Jakobs W., Rahn R., Richter K. et al. Pharmacokinetic parameters after repeated submucosal injection of articaine and lidocaine with epinephrine - results of a clinical study. Anesth. Prog. 2007; 54 (IFDAS Abstracts: 11 International Dental Congress on Modern Pain Control, 4-7 October, 2006), 133.

6. Yapp K.E., Hopcraft M.S., Parashos P. Articaine: a review of the literature. Br Dent J. 2011; 210(7):323-9.

7. American Academy on Pediatric Dentistry Council on Clinical Affairs. Guideline on appropriate use of local anesthesia for pediatric dental patients. Pediatr Dent. 2008-2009; 30 (7 Suppl):134-9.

8. Leith R., Lynch K., O'Connell A.C. Articaine use in children: a review. Eur Arch Paediatr Dent. 2012; 13(6):293-6.

9. Malamed S.F. Systemic complications. In: Handbook of Local Anesthesia. 5th ed. St. Louis, Mo: Mosby; 2004:311-25. 


\section{Ультранаин ${ }^{\circledR}$}

\section{Упьтракаuн}

Местный анестетин для индивидуального подхода н наждому пациенту $1,2,3$

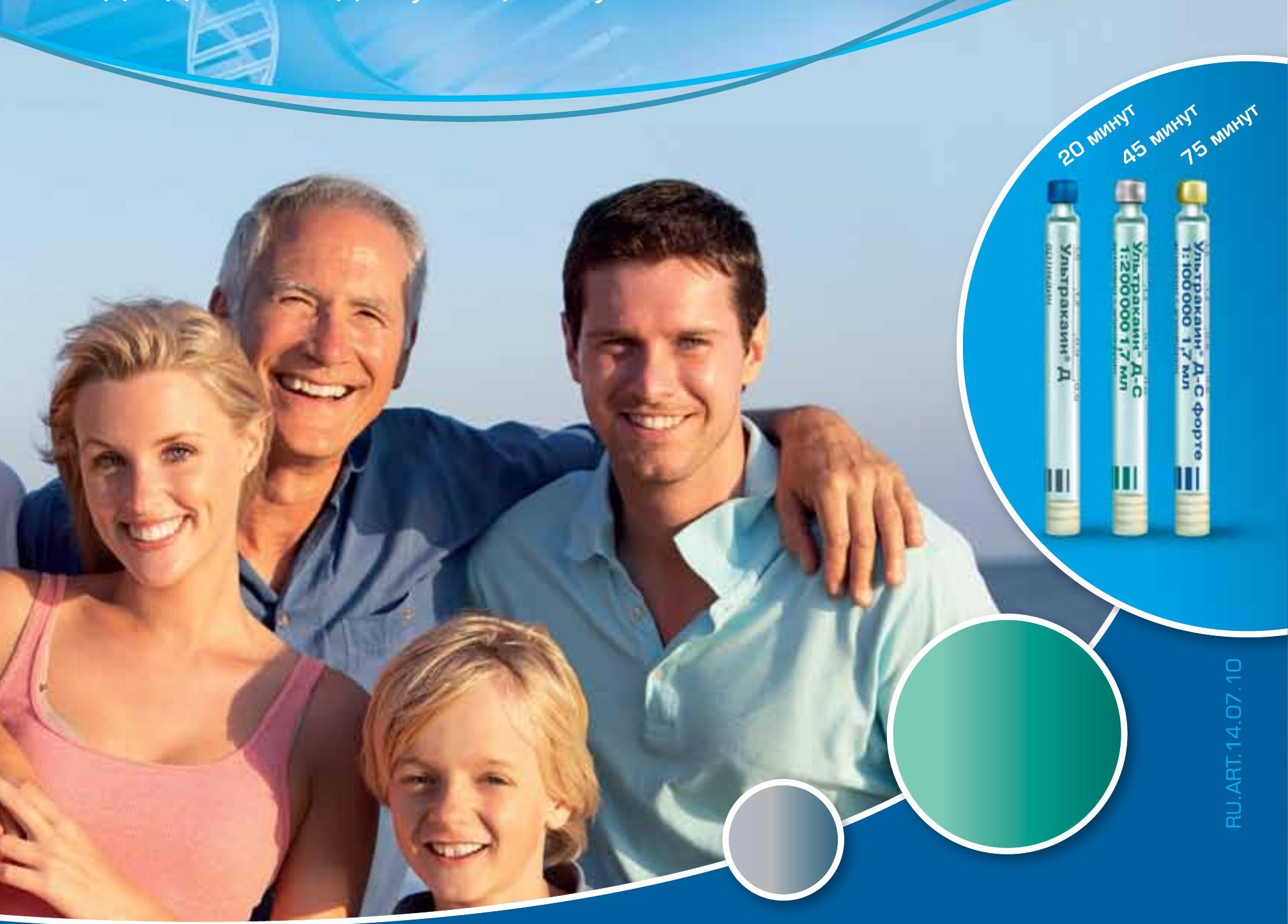

www.sanofi.ru

НРАТНАЯ ИНСТРУНЦИЯ ПО МЕДИЦИНСНОМУ ПРИМЕНЕНИЮ ПРЕПАРАТОВ УЛЬТРАНАИНВ Д. УЛЬТРАНАИН囚 Д-С. УЛЬТРАКАИНВ Д-С ФОРТЕ

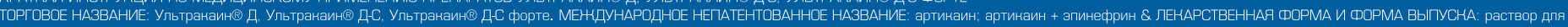

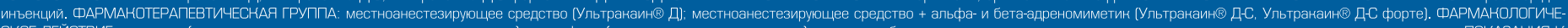

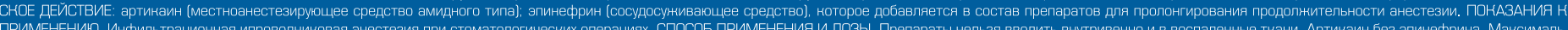

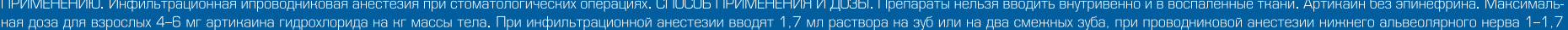

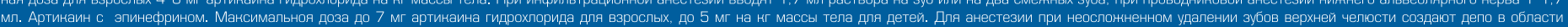

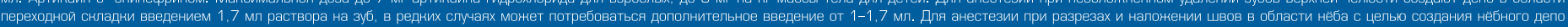

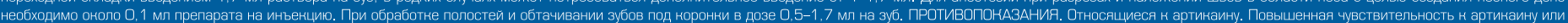

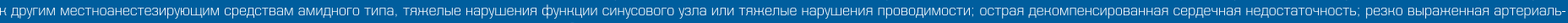

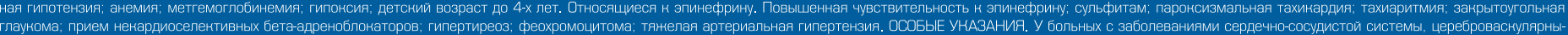

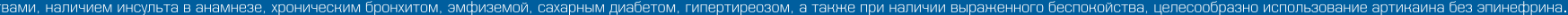

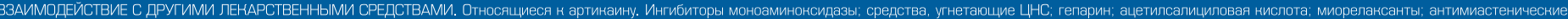

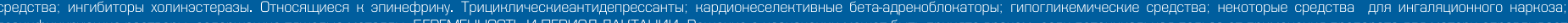
ощие растворы, содержащие тяжелые метал

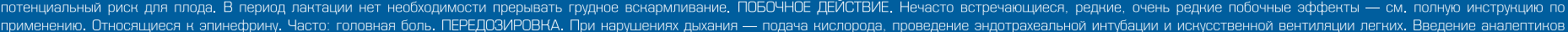

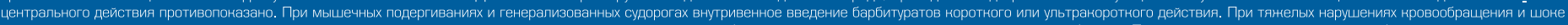

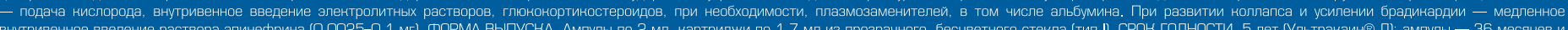
картриджи - ЗО месяцев (Ультракаин® Д-С, Ультракаин® Д-С форте). УСЛОВИЯ ОТПУСНА ИЗ АПТЕН: по рецепту. С подробной информацией о препарате можно ознакомитьСя в инстоукции по поименению.

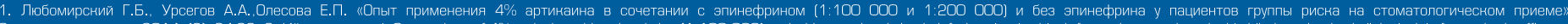

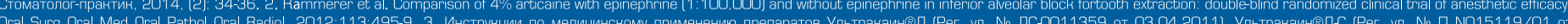
13.08.2008), Ультракаин® Д-С форте (Рег. уд. № №15117/01 от 13.08.2008) 